\title{
artigo
}

Oliveira, W.S.; Santos, N.M.S.; Maria da Silva, C.; Menezes, A.A.; Fortaleza, M.J.C.

Achados fonoaudiológicos na Síndrome da Imunodeficiência Adquirida: revisão integrativa

\section{Achados fonoaudiológicos na Síndrome da Imunodeficiência Adquirida: revisão integrativa}

\author{
Phonoaudiological findings in Acquired Immunodeficiency Syndrome: integrative review \\ Hallazgos fonoaudiológicos en el Síndrome de Inmunodeficiencia Adquirida: revisiõn integrative
}

\begin{abstract}
RESUMO
Objetivo: descrever os conhecimentos científicos já produzidos sobre as alterações e fonoaudiológicas a Síndrome da Imunodeficiência Humana Adquirida. Métodos: Trata-se de uma revisão integrativa da literatura, realizada no mês de maio a setembro de 2020, nas bases de dados Public Medicine Library (PubMed) e Literatura Latino-Americana e do Caribe em Ciências da Saúde (LILACS) via a plataforma virtual BVS - Biblioteca Virtual em Saúde e Scientific Eletronic Library Online (SCIELO), através dos descritores combinados pelo operador boleano AND. Resultados: Foram encontrados 506 artigos e destes 22 contemplavam os objetivos da pesquisa. Conclusão: Os pacientes acometidos por Síndrome da Imunodeficiência Adquirida apresentam alterações fonoaudiológicas que comprometem em sua qualidade de vida.
\end{abstract}

DESCRITORES: SIDA; Disfagia; Linguagem; Perda auditiva; Voz.

\section{ABSTRACT}

Objective: to describe the scientific knowledge already produced on the alterations and phonoaudiologic the Acquired Human Immunodeficiency Syndrome. Methods: This is an integrative review of the literature, carried out from May to September 2020, in the Public Medicine Library (PubMed) and Latin American and Caribbean Literature in Health Sciences (LILACS) databases via the VHL Virtual Health and Scientific Electronic Library Online (SCIELO) virtual platform, through the descriptors combined by the Bolean operator AND. Results: 506 articles were found and of these 22 contemplated the research objectives. Conclusion: The patients with Acquired Immunodeficiency Syndrome present speech and hearing alterations that compromise their quality of life. DESCRIPTORS: AIDS; Dysphagia; Language; Hearing loss; Voice.

\section{RESUMEN}

Objetivo: describir el conocimiento científico ya producido sobre las alteraciones y fonoaudiológicas del Síndrome de Inmunodeficiencia Humana Adquirida. Métodos: Se trata de una revisión integral de la literatura, realizada entre mayo y septiembre de 2020, en las bases de datos de la Biblioteca Pública de Medicina (PubMed) y de la Literatura Latinoamericana y del Caribe en Ciencias de la Salud (LILACS) por medio de la plataforma virtual de la Biblioteca Virtual en Salud y la Biblioteca Electrónica Científica en Línea (SCIELO) de la BVS, a través de los descriptores combinados por el operador Bolean AND. Resultados: Se encontraron 506 artículos y de éstos 22 contemplaban los objetivos de la investigación. Conclusión: Los pacientes con el Síndrome de Inmunodeficiencia Adquirida tienen alteraciones del habla y la audición que comprometen su calidad de vida.

DESCRIPTORES: SIDA; Disfagia; Lenguaje; Pérdida de audición; Voz.

RECEBIDO EM: 15/12/2020 APROVADO EM: 07/01/2021

\section{Marisa Siqueira Brandão Canut}

Fonoaudiologa, Mestre em Terapia Intensiva pela Sociedade Brasileira de Terapia Intensiva - SOBRATI. Especialista em Motricidade Orofacial pelo Centro de Especialização em Fonoaudiologia Clínica - CEFAC e pelo Conselho Federal de Fonoaudiologia - CFFa e especialista em Disfagia pelo Conselho Federal de Fonoaudiologia - CFFa. Professora Auxiliar do Curso de Fonoaudiologia da Universidade Estadual de Ciências da Saúde de Alagoas - UNCISAL. Maceió, Alagoas, Brasil.

ORCID: 0000-0002-0559-1212

\section{Wadson dos Santos Oliveira}

Estudantes de Fonoaudiologia na Universidade Estadual de Ciências da Saúde de Alagoas - UNCISAL. Maceió, Alagoas, Brasil. ORCID: 0000-0003-3972-886X 


\section{Nicolly Menezes Silva dos Santos}

Estudantes de Fonoaudiologia na Universidade Estadual de Ciências da Saúde de Alagoas - UNCISAL. Maceió, Alagoas, Brasil. ORCID: 0000-0001-6418-3705

\section{Carliane Maria da Silva}

Estudantes de Fonoaudiologia na Universidade Estadual de Ciências da Saúde de Alagoas - UNCISAL. Maceió, Alagoas, Brasil. ORCID: 0000-0002-3543-4488

\section{Amanda Almeida de Menezes}

Estudantes de Fonoaudiologia na Universidade Estadual de Ciências da Saúde de Alagoas - UNCISAL. Maceió, Alagoas, Brasil. ORCID: 0000-0001-5705-4526

\section{Maria Júlia Cabral Fortaleza}

Estudantes de Fonoaudiologia na Universidade Estadual de Ciências da Saúde de Alagoas - UNCISAL. Maceió, Alagoas, Brasil. ORCID: 0000-0001-8693-2279

\section{INTRODUÇÃO}

A síndrome da imunodeficiência adquirida - SIDA (Acquired Immunodeficiency Syndroms - AIDS) é uma doença infectocontagiosa crônica, que ocorre através da ação do Vírus da Imunodeficiência Humana - VIH (Human Immunodeficiency Virus - HIV) um tipo específico de retrovírus que ataca o sistema imunológico, destruindo os receptores das células CD4+ dos linfócitos $\mathrm{T}$, responsáveis pela imunidade celular, o que acarretará em alterações imunológicas e comprometimento neurológico, fisiológico e emocional ${ }^{1,2}$.

A infecção HIV tem um curso que pode abranger desde a fase aguda, caracterizada por sintomas de uma infecção viral que inclui cefaleia, mal-estar, febre, adenite, faringite, exantema e mialgia, até uma fase avançada. Dessa forma ela caracteriza-se em três estágios: síndrome retroviral aguda, infecção crônica assintomática e infecção sintomática, sendo a fase mais avançada da infecção, a Síndrome da Imunodeficiência Adquirida ${ }^{3,4}$.

Esta síndrome, foi descoberta nos anos 80 no Brasil e em outros países com indícios de alta morbidade e letalidade, o que levou a comunidade cientifica a pesquisar sobre a patologia. Inicialmente era caracterizada doença típica de homossexuais masculinos, mas os estudos evidenciaram uma patologia que atingia ambos os gêneros homens e mulheres sem especificidades, que se alastrou rapidamente pelos
A síndrome da imunodeficiência

adquirida SIDA (Acquired Immunodeficiency Syndroms - AIDS) é uma doença infectocontagiosa crônica, que ocorre através da ação do Vírus da Imunodeficiência

Humana VIH (Human Immunodeficiency Virus - HIV) continentes caracterizando uma pandemia para época. Essa pandemia possuía dois aspectos importantes a serem ressaltados: a inclusão de um grupo especifico no perfil epidemiológico, a mulher, e a problemática da transmissão materno-fetal. As formas de transmissão do vírus incluem relações sexuais, mais incidente na população adulta, transfusão de sangue e/ ou medula, uso compartilhado de seringas e por transmissão vertical. A transmissão materno-fetal por transmissão vertical pode acontecer em três momentos: por infecção intrauterina, durante o período gestacional, infecção periparto (durante o trabalho de parto) e no pós-parto, trazendo ao indivíduo contagiado alterações/ manifestações consideradas fonoaudiológicas, como: alteração de sensibilidade, tônus e força muscular, disfagia, alterações de linguagem, perdas auditivas e alterações vocais ${ }^{2,5-7}$.

Visto isso, o presente estudo tem como objetivo sintetizar e descrever os conhecimentos científicos já produzidos sobre as alterações e comorbidades fonoaudiológicas relacionadas a Síndrome da Imunodeficiência Humana Adquirida, delineando o cuidar do olhar fonoaudiológico, buscando responder o seguinte questionamento: "Quais as manifestações fonoaudiológicas na Síndrome da Imunodeficiência Adquirida?”.

\section{MÉTOdOS}

Trata-se de uma revisão integrativa de literatura, realizado no mês de maio a se- 
tembro de 2020. Para a busca dos artigos foram utilizados os descritores combinados com o operador booleano AND em: SIDA AND Disfagia, SIDA AND Linguagem, SIDA AND Perda auditiva e SIDA AND Voz. A busca foi realizada através das bases de dados Public Medicine Library (PubMed) e Literatura Latino-Americana e do Caribe em Ciências da Saúde (LILACS) via a plataforma virtual BVS - Biblioteca Virtual em Saúde e na Scientific Eletronic Library Online (SCIELO).

Foram incluídos artigos originais (de delineamento experimental ou observacional), monografias, capítulos de livros e artigos de revisão disponíveis na íntegra, na língua portuguesa, nos últimos 10 anos, que contemplassem a pergunta norteadora e excluídos artigos que não respondessem ao objetivo da pesquisa, na língua inglesa e/ou outra língua, que não estavam disponíveis na integra e estudos duplicados. A busca e seleção dos artigos se deu através das recomendações do instrumento PRISMA, de forma pareada e independente por dois pesquisadores; foi realizada a partir de uma triagem de leitura dos títulos, resumos e descritores, extração dos artigos disponíveis para download para leitura integral, analise crítica dos estudos, síntese qualitativa e interpretação das evidências cientificas para redação da revisão.

\section{RESULTADOS}

A busca eletrônica resultou em 506 artigos, após a aplicação dos critérios de inclusão e exclusão, foram selecionados 23 artigos que contemplavam o objetivo do estudo. A figura 1 ilustra a estratégia de busca e os artigos selecionados para esta revisão.

\section{DISCUSSÃO}

Após a leitura completa dos artigos, os dados extraídos das produções cientificas selecionadas foram listados em categorias, interpretados e apresentados de forma descritiva para discussão do estudo.

\section{Manifestações orais, dificuldades ali- mentares e disfagia}

As alterações motoras orais se caracterizam por repercussão na sensibilidade, tônus e força muscular dos órgãos do sistema estomotoglossognático. Estas alterações podem determinar prejuízo nas funções de mastigação e deglutição, favorecendo a ocorrência da disfagia. A disfagia é um sintoma secundário a uma doença de base que pode levar o indivíduo ao regurgitamento nasal; voz molhada; tosse e broncoaspiração de saliva e/ou alimento; o que pode refletir na recusa alimentar, resultando em desnutrição, desidratação e pneumonias de repetição ${ }^{9-12}$.

As deficiências nutricionais, como carência de selênio, podem exercer impacto negativo sobre o sistema imune já comprometido, aumentando a susceptibilidade a infecções/doenças oportunistas, o Citomegalovírus e a Ventriculoencefalite, por exemplo, e as neoplasias. O Citomegalovírus é uma infecção oportunista cujas manifestações clínicas consistem nas

Figura 1: Fluxograma dos resultados da estratégia de busca

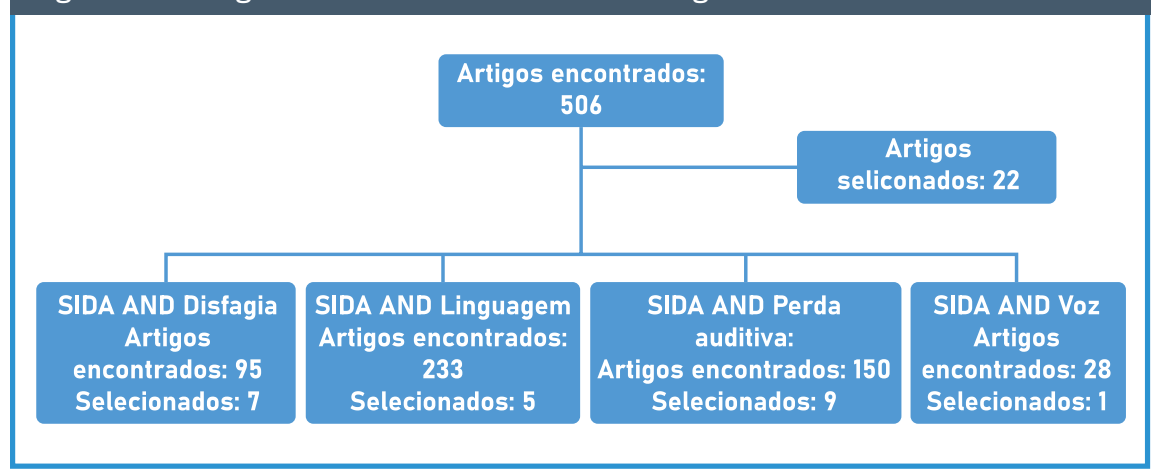

síndromes neurológicas, oftalmológicas e gastrointestinais (tais como esofagite, gastrite, enterite e colite). Sendo, as neoplasias correspondem às principais causas de morte destes pacientes ${ }^{4,9,12}$.

As manifestações orais são os primeiros sinais que antecedem as manifestações sistêmicas. As alterações na deglutição são mais comuns em casos de candidíase, herpes, Sarcoma de Kaposi e ulcerações aftosas".

\section{Alterações no Sistema Nervoso Cen- tral e comprometimento de linguagem}

As pesquisas comprovam que o cérebro é o primeiro alvo na infecção pelo HIV, o que comumente leva a uma redução do crescimento cerebral ou a um quadro de regressão global. Os estudos selecionados descrevem achados mais comuns em crianças, os quais, segundo Rocha et al., são: hiporreflexia nos membros, retardo ou pregresso do desenvolvimento neuropsicomotor, atraso de linguagem, deficiência mental e paralisia cerebral ${ }^{12}$. Não se observou na literatura selecionada especificidade desta correlação em outras faixas etárias.

As consequências do envolvimento do Sistema Nervoso Central (SNC) em crianças podem estar evidentes desde o início do quadro clínico ou demorar muitos anos para que ocorra a manifestação. Nos primeiros anos da epidemia da SIDA, a encefalopatia progressiva foi considerada uma das manifestações precoces da doença em crianças, causando déficits em diversas áreas como nas funções motoras, de fala, linguagem, memória e aprendizado $3,13,14,17$.

Ressaltamos que nos artigos selecionados não foram descritas as alterações neurológicas e de comprometimento de linguagem na população adulta.

\section{Alterações auditivas}

A incidência de alteração auditiva em pacientes adultos com HIV refletem alterações de origem periférica e/ou central, enquanto que em crianças são mais periféricas e podem ser causadas por infecções casuais ou por doenças oportunistas. Estes indivíduos apresentam queixas como: 
plenitude auricular, tontura, hipoacusia, zumbido, otalgia e otorreia ${ }^{2,11,13,15}$.

Os primeiros estudos atribuíram a surdez sensorioneural em SIDA a múltiplas causas. $\mathrm{O}$ estado de imunodeficiência predispõe, em tais pacientes, uma série de mecanismos meningogênicos capazes de ocasionar esse tipo de surdez, dentre eles: meningite criptocócica, tuberculosa, viral, bacteriana; infecção pelo citomegalovírus (CMV) e vírus da hepatite B; toxoplasmose do SNC. Estas alterações podem ser decorrente de comprometimentos na orelha externa, média e/ou interna. Há anormalidades nos Potenciais Evocados Auditivos de Tronco Encefálico (PEATE) que podem ser encontradas precocemente, antes do aparecimento clínico de sintomas $s^{5,716}$.

A infecção pelo vírus HIV e os distúrbios otoneurológicos, como perda de audição, zumbido e tontura vêm sendo associadas às infecções oportunistas, às drogas ototóxicas e à ação direta do vírus no sistema cocleovestibular. Em pesquisa, VIEIRA et al., em 2008, objetivou avaliar está correlação. Foram selecionados 284 prontuários, sendo 162 (57\%) de pacientes que usavam anti-retrovirais (grupo de estudo) e 122 (43\%) de pacientes que não estavam em uso dessa medicação (grupo controle). Dos 162 pacientes do grupo estudado, $14(8,6 \%)$ relataram queixas otoneurológicas e, dos 122 pacientes do grupo controle, sete $(5,8 \%)$ apresentaram essas queixas. Para o grupo que não estava sendo tratado, esse raciocínio faz crer que a causa das queixas e doenças otoneurológicas presentes no grupo não tratado estariam associadas à ação do vírus, uma vez que esses pacientes estavam com carga viral mais elevada ${ }^{18}$.

Mas o estudo, não observou diferença estatisticamente significativa entre as queixas otoneurológicas no grupo tratado em relação ao grupo não tratado. A queixa de tontura não parece ter sido um problema relacionado ao uso de drogas anti-retrovirais e em relação ao diagnóstico otoneurológico, as perdas auditivas dos pacientes não tratados com anti-retrovirais foram desencadeadas por fatores comuns aos quais a população em geral está exposta, como rolha de cerume e ruído ocupacional. Com isso, os autores relataram que não foi possível considerar a associação entre exposição ao vírus HIV e a terapia anti-retroviral a ototoxidade ${ }^{18}$.

\section{A infecção pelo vírus HIV e os distúrbios} otoneurológicos, como perda de audição, zumbido

e tontura vêm

sendo associadas

às infecções

oportunistas, às

drogas ototóxicas

e à ação direta do

vírus no sistema

cocleovestibular.

Enquanto isso, estudos descritivos posteriores, consideram possível o comprometimento a orelha interna, decorrente da própria ação do vírus HIV é mencionado em estudos envolvendo pacientes com
SIDA, assim como a alteração auditiva ocasionada pelo uso de tratamento antirretroviral e medicações ototóxicas, ambos ocasionando perdas auditivas do tipo neurossensorial e, consequentemente, danos irreversíveis à orelha interna. E em relação ao comprometimento de orelha média e, consequentemente, a presença de perda auditiva condutiva ou mista, foi relatado que esta alteração seria decorrente da imunossupressão, que favorece a presença de infecções oportunistas ${ }^{10}$.

Em outra pesquisa, realizada por MATAS C.G., 2010, verificou-se a ocorrência significantemente maior de perda auditiva condutiva em crianças quando comparado ao grupo de adultos e que por outro lado, a ocorrência de perda auditiva sensorioneural foi significantemente maior em adultos. Na mesma pesquisa, analisando o PEATE, que crianças apresentam maior ocorrência de alterações do tipo Tronco Encefálico Baixo (TEB), Tronco Encefálico Alto (TEA) e alterações no PEATE sugestivas de comprometimento na orelha média e em adultos as alterações do tipo ambas ocorreu com maior frequência, bem como resultados sugestivos de alteração sensorioneural ${ }^{3}$.

\section{Infecção das vias aéreas e alterações vocais}

Um estudo de Makar SK et al., publicado em 2012, sobre a voz de crianças com HIV. Os autores investigaram alterações audiológicas, vocais, de linguagem e deglutição, em crianças entre 4 e 16 anos de idade. No referido estudo, a avaliação vocal foi realizada com uso do instrumento Buffalo III e foram encontrados $31,34 \%$ de alterações vocais (voz rugosa, soprosa e entrecortada), ausência de disartria e sem descrições da avaliação do abuso vocal. Em um estudo posterior, os autores ainda estudaram alterações de voz, disartria e funções orais, em 15 adultos do gênero masculino, entre 18 e 40 anos. Foram analisadas funções reflexas orais, respiração, estruturas de lábios, língua, mandíbula, palato mole e laringe, inteligibilidade de fala e disartria. Em algum momento da infecção pelo HIV, os 


\section{artigo}

Oliveira, W.S.; Santos, N.M.S.; Maria da Silva, C.; Menezes, A.A.; Fortaleza, M.J.C.

Achados fonoaudiológicos na Síndrome da Imunodeficiência Adquirida: revisão integrativa

pacientes vão apresentar algum sinal ou sintoma otorrinolaringológico, capaz de afetar a laringe e/ou a voz ${ }^{11}$.

Aponta-se como limitação da presente revisão, o pequeno número de estudos sobre as alterações vocais nos pacientes de SIDA e que mencionassem a qualidade vocal: loudness, pitch, ressonância e outros aspectos vocais importantes.

\section{CONCLUSÃO}

Os estudos selecionados, para o de- senvolvimento da revisão, evidenciaram que as alterações/manifestações de repercussões fonoaudiológicas, em pacientes de Síndrome da Imunodeficiência Adquirida, são referentes à comunicação e alimentação. No que diz respeito a comunicação constata-se prejuízo de origem neurológica refletindo rebaixamento cognitivo, alteração na linguagem expressiva e compreensiva com déficit da capacidade intelectual e memória; além de comprometimento vocal. Quanto as alterações alimentares a literatura relata doenças oportunistas como candidíase oral e esofágica, miopatia, pneumonia, tuberculose, câncer, herpes, demência, neuropatia periférica, leucoplasia pilosa oral, entre outras patologias as determinantes para desencadear disfagia ${ }^{11,19}$. Esta pesquisa ressalta a importância da fonoaudiologia na equipe multiprofissional que acompanha os pacientes com SIDA, sendo o fonoaudiólogo o profissional capacitado para atuar diante de manifestações comunicativas e alimentares, como as mencionadas nas literaturas encontradas. -

\section{REFERÊNCIAS}

1. Furkim, A M; Capítulo: "Fonoterapia nas Disfagias Orofaríngeas Neurogênicas"; Furkim, A M; Santini, C S;Capítulo: "Disfagia Ñ̃eurogênica"; MCKAIG T. Neil; Capítulo: "Ausculta- Cervical e Torácica"; GONÇALVES Roberta Silva; Capítulo: "Disfagia Neurogênica em Adultos: Uma proposta pra avaliação clínica"; FURKIM, Ana Maria; SANTINI, Célia Salviano Disfagia Orofaríngeas. São Paulo. Editora: Pró-Fono, 1999.

2. Kumar SB et al. Elevated cytokine and chemokine levels in the placenta are associated with in-utero HIV-1 mother-to-child transmission. AIDS. 2012.5. Furlan S A, Fukuda M T H, Granzotti R B G. Habilidades de consciência fonológica em crianças portadoras da síndrome da imunodeficiência adquirida: pré e pós-terapia fonoaudiológica. Rev Soc Bras Fonoaudiol. 2012;

3. Mangilli L D Et Al. Atuação Fonoaudiológica Em Pacientes Com Síndrome Da Imunodeficiência Adquirida E Queixa De Deglutição - Análise Retrospectiva De Prontuários. Audiol., Commun. Res.,São Paulo, V. 21, E1620,2016.

4. Paula I S. Mielite Transversa Por Citomegalovírus Em Pessoa Vivendo Com HIV/AIDS: Relato De Caso E Revisão Da Literatura (Monografia Em Residência Médica De Infectologia) - Instituto De Infectologia Emílio Ribas, São Paulo, 2020.

6. Gomes A M T; Cabral I E; Schilkowsky L B. Crianças com hiv/ aids de uma unidade ambulatorial pública. Rio de janeiro, brasil 2003: conhecendo seu perfil Rev. Soc. Bras. Enferm. Ped. v.4, n.2, p. São Paulo, dezembro de 2004.

7. Matas C G, Leite R A, Magliaro F C. Avaliação Audiológica E Eletrofisiológica Em Crianças Portadoras Da Síndrome Da Imunodeficiência Adquirida. Rev ACTA ORL. 2005.

8. Al-Husaini A M. Role of placenta in the vertical transmission of human immunodeficiency virus. J Perinatol. 2009.

9. Araújo D R, Bicalho I C S, Di Francesco R. Disfagia em pacientes portadores da síndrome da imunodeficiência adquirida - AIDS. Rev CEFAC. 2005;

10. Pereira E C Et Al. Análises Perceptivo-Auditiva E Acústica Das Vozes De Crianças Infectadas Pelo HIV. Codas, São Paulo, V. 29, N. 6, E20170022, 2017.
11. Quidicomo S, Matas Cg. Estudos da função auditiva em indivíduos com HIV/AIDS submetidos e não submetidos à terapia antirretroviral. ACR. 2013.

12. Resende L.M., Santos T. M. M., PINTO J. A., Perfil audiológico de crianças HIV infectadas. Rev. CEFAC. 1999.

13. CMM. A Fonoaudiologia intervindo em pacientes com AIDS.

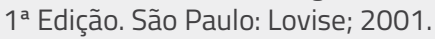

14. Dias R M et al. Crianças HIV Positivas: Características Antropométricas e Sociodemográficas. Rev para med. 2012;

15. Grando L J et al. Manifestações estomatológicas, contagem de linfócitos T-CD4+ e carga viral de crianças brasileiras e norte-americanas infectadas pelo HIV. Rev Odontol Bras. 2002.

16. Boekel, Valentina Van Et Al. Vasculite isolada do sistema nervoso central e acometimento do VIII nervo craniano manifestações raras da síndrome de imunodeficiência adquirida: an uncommon manifestation of AIDS. Arq. Neuro-Psiquiatr., São Paulo, v. 50, n. 1, p. 104-109, Mar. 1992.

17. Manfredi A K S et al. Triagem auditiva neonatal em recém-nascidos de mães Soropositivas Para O HIV. J. Soc. Bras. Fonoaudiol., São Paulo, V. 23, N. 4, P. 376-380, Dec. 2011.

18. Vieira A B C et al. Manifestações otoneurológicas associadas à terapia anti-retroviral. Rev. Soc. Bras. Med. Trop., Uberaba, v. 41, n. 1, p. 65-69, Feb. 2008.

19. Arias RA, Munoz LD, Munoz-Fernandez MA. Transmission of HIV-1 infection between trophoblast placental cells and Tcells take place via an LFA-1-mediated cell to cell contact. Virology. 2003;

20. Granzotti R B G et al. Aspectos da linguagem em crianças infectadas pelo HIV. Rev. CEFAC. 2013.

21. Guedes-Granzotti R B et al. Linguagem oral e escrita de crianças soropositivas para o HIV: um acompanhamento longitudinal. Audiol., Commun. Res., São Paulo, v. 22, e1852, 2017.

22. Sanjar F A; Queiroz B E U P; Miziara I D. Manifestações otorrinolaringológicas na infecção pelo HIV: aspectos clínicos e terapêuticos. Braz. j. otorhinolaryngol. (Impr.), São Paulo, v. 77, n. 3, p. 391-400, June 2011. 